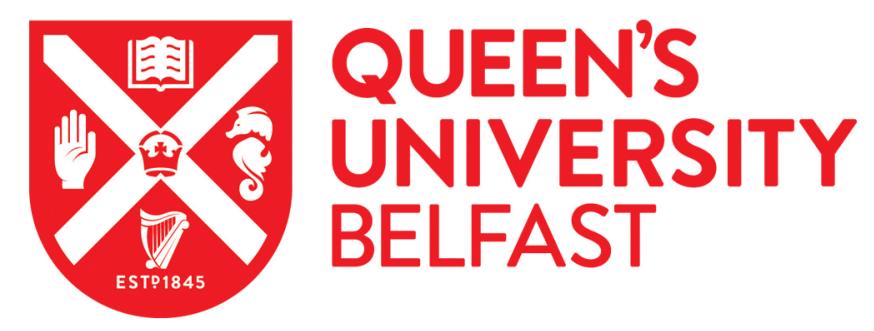

\title{
Diabetes in humanitarian crises: the Boston Declaration
}

Kehlenbrink, S., Jaacks, L., \& Hunter, R. (2019). Diabetes in humanitarian crises: the Boston Declaration. Lancet Diabetes Endocrinol, 7(8), 590-592. https://doi.org/10.1016/S2213-8587(19)30197-4

\author{
Published in: \\ Lancet Diabetes Endocrinol
}

Document Version:

Peer reviewed version

Queen's University Belfast - Research Portal:

Link to publication record in Queen's University Belfast Research Portal

\section{Publisher rights}

Copyright 2019 Elsevier

This manuscript is distributed under a Creative Commons Attribution-NonCommercial-NoDerivs License

(https://creativecommons.org/licenses/by-nc-nd/4.0/), which permits distribution and reproduction for non-commercial purposes, provided the author and source are cited.

\section{General rights}

Copyright for the publications made accessible via the Queen's University Belfast Research Portal is retained by the author(s) and / or other copyright owners and it is a condition of accessing these publications that users recognise and abide by the legal requirements associated with these rights.

Take down policy

The Research Portal is Queen's institutional repository that provides access to Queen's research output. Every effort has been made to ensure that content in the Research Portal does not infringe any person's rights, or applicable UK laws. If you discover content in the Research Portal that you believe breaches copyright or violates any law, please contact openaccess@qub.ac.uk. 
Diabetes in humanitarian crises: the Boston Declaration

Sylvia Kehlenbrink ${ }^{1}$ and Lindsay Jaacks ${ }^{2}$ on behalf of the signatories

${ }^{1}$ Brigham and Women's Hospital, Division of Endocrinology, Diabetes and Hypertension, Boston, Massachusetts, United States of America

${ }^{2}$ Department of Global Health and Population, Harvard T.H. Chan School of Public Health, Boston, Massachusetts, United States of America

\section{Corresponding Author:}

Sylvia Kehlenbrink, MD

Brigham and Women's Hospital

Division of Endocrinology, Diabetes and Metabolism

221 Longwood Ave. RFB-2

Boston, MA 02115

Tel. +1-617-732-8396

Fax: +1-617-732-5764

Email: skehlenbrinkoh@bwh.harvard.edu

Running Title: Boston Declaration

Word Count: 689 (not including the table) 
Nearly three out of every four deaths globally in 2017 were caused by non-communicable diseases (NCDs). ${ }^{1}$ Many countries have made progress reducing NCD risk factors such as tobacco use, hyperlipidemia, and hypertension, but no countries have successfully reversed the increasing trends in diabetes prevalence and mortality from diabetes is increasing. ${ }^{1}$ This represents a massive global health failure considering the fact that type 2 diabetes is largely preventable with lifestyle modification and that cost-effective treatments exist for both type 2 and type 1 diabetes. ${ }^{2}$ Specific concern is needed for type 1 diabetes, which without insulin, it is fatal.

In parallel, forced migration has reached a record high with 68.5 million people displaced from their homes around the world, $85 \%$ being hosted in low or middle-income countries such as, Uganda, Lebanon, and Pakistan, and $65 \%$ occurring in protracted refugee situations. ${ }^{3}$ In addition, there are over 100 million conflict-affected non-displaced people and 175 million people who are affected by natural disasters annually. ${ }^{4}$ These individuals are particularly vulnerable in crises due to disrupted health services and unpredictable-and often unhealthy-food supplies, which may exacerbate their condition and lead to complications.

To date, diabetes and other NCDs have largely been underserved in humanitarian settings. ${ }^{5,6,7}$ The true scope of the problem has not been established and it is not known which interventions are efficacious, feasible, and cost-effective in these contexts. With respect to type 1 diabetes, arguably the most immediately life-threatening NCD, the supply and cost of insulin, blood glucose monitoring and diagnostic tools are barriers for both humanitarian responders and their host countries, as well as patient adherence, life expectancy, quality of life, follow-up and provider training in diabetes care.

In order to begin to address these major gaps, on 4-5 April 2019, Harvard University convened a meeting of humanitarian and other actors in global health to discuss the immediate needs and barriers to tackling diabetes in humanitarian crises, and to adopt a unified, action-oriented agenda to address this pressing global health issue (http://globalendocrinology.bwh.harvard.edu/symposium). Whilst it was recognised that there are substantial gaps in care for diabetes in all low-resource settings, ${ }^{8}$ not just humanitarian crises, and that many other NCDs (e.g., cardiovascular disease, chronic obstructive pulmonary disease and asthma) are also prevalent globally and inadequately addressed in humanitarian settings, ${ }^{9}$ we chose to prioritize efforts on diabetes in humanitarian crises, for the following reasons:

First, because people with type 1 diabetes who cannot access insulin and continuity of care in a crisis are at acute risk of death. The principles of the Humanitarian Charter and United Nations Universal Declaration of Human Rights include the right to life with dignity. ${ }^{10}$ The human rights violations of people with diabetes that we have witnessed, including the most basic right to life, which is threatened by the barriers to accessing insulin and follow-up, are unacceptable and incompatible with these principles. Second, the management of diabetes requires an uninterrupted supply of essential medicines, field-based laboratory diagnostics, continuity of care, adoption of healthy lifestyle behaviours, cardiovascular risk reduction and management of co-morbidities including depression, hypertension, and secondary prevention of complications. Thus, diabetes management requires a more complex health system infrastructure than for most other NCDs, but shares many characteristics and risk factors of other NCDs. Hence, the development of an effective diabetes program in creates a strong platform for providing high-quality care for other NCDs. 
We have set four major targets to work towards over the next three years: (1) unified and strengthened advocacy, (2) universal access to insulin, other essential medicines and diagnostics for glycemic and blood pressure control in humanitarian crises, (3) establish a unified set of clinical and operational guidelines for diabetes in humanitarian crises, and (4) improved data and surveillance. Specific goals are outlined in the adjacent panel. We will hold annual meetings to monitor progress.

The health needs of crisis-affected populations are changing. We must uphold the humanitarian imperative, adapting to the needs of an ever-changing world, and collectively improve the delivery of diabetes care in crises to save lives, reduce suffering and promote dignity, reduce disability while also working to strengthen the health-sytem response and resilience in low- and middleincome countries affected by crises.

Contributors: SK and LJ wrote an initial draft of the manuscript. All signatories participated in manuscript review and editing.

Declaration of interest: SK received personal fees from Medécins Sans Frontières (MSF)/ Doctors Without Borders, Health Action International and the Medicines Patent Pool outside the submitted work. MAH received honoraria from Novo Nordisk and the Simply Speaking NASH Program, both outside the submitted work. DJ and KR report grants from Abbott Fund, outside the submitted work. JL reports personal fees from Alosa Health and Health Action International. PR reports grants from the U.S. Agency for International Development, outside the submitted work.

Acknowledgments: Financial support was provided by Brigham and Women's Hospital, the Department of Global Health and Population at the Harvard T.H. Chan School of Public Health, the National Institute on Aging of the National Institutes of Health, and several anonymous donors. 


\section{References}

1. Roth GA, Abate D, Abate KH, et al. Global, regional, and national age-sex-specific mortality for 282 causes of death in 195 countries and territories, 1980-2017: a systematic analysis for the Global Burden of Disease Study 2017. The Lancet 2018; 392(10159): 1736-88. 2. Ali MK, Siegel KR, Chandrasekar E, et al. Diabetes: An update on the pandemic and potential solutions. Disease Control Priorities 2017; 5.

3. UNHCR. Figures at a Glance. 2018. https://www.unhcr.org/figures-at-a-glance.html (accessed April 22 2019).

4. The human cost of natural disasters 2015: A global perspective. Centre for Research on the Epidemiology of Disasters (CRED), 2015

5. Kehlenbrink S, Smith J, Ansbro E, et al: The burden of diabetes and use of diabetes care in humanitarian crises. Lancet Diabetes Endocrinol 2019 March 13 [Epub ahead of print]

6. Boulle P, Kehlenbrink S, Smith J, Beran D, and Jobanputra K: Challenges associated with providing diabetes care in humanitarian settings. Lancet Diabetes Endocrinol 2019 March 13 [Epub ahead of print]

7. Report on International Conference on Refugees and Diabetes, 10-12 April 2017. https://www.researchgate.net/publication/322569644 Report on International Conference on Refugees and Diabetes 10-12 April 2017 (accessed May 24, 2019)

8. Manne-Goehler J, Geldsetzer P, Agoudavi K, et al. Health system performance for people with diabetes in 28 low- and middle-income countries: A cross-sectional study of nationally representative surveys. PLoS Med 2019; 16(3): e1002751.

9. Perone SA, Martinez E, du Mortier S, et al. Non-communicable diseases in humanitarian settings: ten essential questions. Conflict and Health 2017; 11(1): 17.

10. United Nations Declaration of Human Rights. https://www.un.org/en/universaldeclaration-human-rights/ (accessed May 6, 2019) 


\section{Unified and strengthened advocacy}

- High-level declaration that insulin should be made available to all those in need in recognized humanitarian settings and during recovery.

- Strengthen unified advocacy campaigns and global awareness, particularly among governments and donors, to ensure a right to insulin and inclusion of diabetes care in the humanitarian response.

- Improve processes for dissemination of findings and publications about diabetes care and prevention in humanitarian crises to all audiences.

- Advocate for the use of all available tools to reduce prices of medicines and diagnostics.

\section{Universal access to insulin, other essential medicines and diagnostics for glycaemic and blood pressure control}

- Routinely include essential medications for diabetes and hypertension in humanitarian response systems, with insulin being an immediate priority.

- Advocate for transparent procurement and prices for insulin used in humanitarian settings reflecting the known cost of production (\$2-4 per $100 \mathrm{IU} 10 \mathrm{~mL}$ equivalent for human insulin).

- Improve diagnostics (blood glucose meters and strips, haemoglobin A1c testing, sphygnomanometers) availability, coverage, quality, field suitability and affordability in humanitarian settings.

- Review currently available literature, protocols of any research that is underway, operational practices, and approach pharmaceutical and diagnostics companies, governments, academic and intergovernmental organizations for further information, with the aim of developing a consensus statement and/or identify needs for further research on insulin thermostability, to inform international guidelines on the storage of insulin and blood glucose test strips in humanitarian settings.

\section{Establish a unified set of clinical and operational guidelines}

- Develop and test evidence-based clinical guidance and educational materials on diabetes care in humanitarian crises, including simple, appropriate, safe and effective algorithms, diagnostic cut-offs and treatment targets.

- Develop and test different cost-effective models of care that take local health systems and food supplies into consideration and differentiated emergency preparedness plans.

- Develop new tools and support innovation around treatment, monitoring and education, including decision-support systems, low-cost medical delivery and diagnostic devices, patient-held medical records, and other standardised systems to facilitate care and coordination between humanitarian organizations.

- $\quad$ Clarify the potential role of insulin analogues in humanitarian settings.

\section{Improved data and surveillance}

- Develop and implement standardised indicators of the prevalence of diabetes, access to care, patient burden and patientcentred outcomes in humanitarian crises for program monitoring and evaluation, and to make these data available to researchers, governments, and other stakeholders.

- Expand the diversity of epidemiological studies of diabetes in humanitarian crises across regions, types of crises (e.g. natural disasters, armed conflict, etc.), and crisis stages.

- Include crisis-affected populations in studies of the economic and social implications of diabetes in host countries.

- Estimate the cost of diabetes care in humanitarian crises incurred by the health system and out-of-pocket expenditures, and the cost of inaction. 